\title{
PERFIL EPIDEMIOLÓGICO DE CRIANÇAS E ADOLESCENTES COM MENINGITE ENTRE 2009 E 2019 NO ESTADO DO MATO GROSSO
}

\section{Autores \\ Amanda Dantas Sabb Amanda Deirane Martins Bárbara Aparecida Braun Pinto Mendes' Isabela de Oliveira Rezende Hellen Rose Souza Cortez Emmanuela Bortoletto Santos dos Reis Rosa Maria Elias Hugo Dias Hoffmann-Santos Isabel Cristina Lopes dos Santos}

1. Discentes do curso de Medicina do Centro Universitário de Várzea Grande - UNIVAG

2. Docente do curso de Medicina do Centro Universitário de Várzea Grande - UNIVAG

3. Médica Infectologista Pediátrica

\section{RESUMO}

Objetivo: Descrever o perfil epidemiológico e clínico dos casos de meningite em crianças e adolescentes entre 0 e 19 anos no estado de Mato Grosso no período entre 2009 e 2019. Método: análise retrospectiva com dados coletados do Sistema de Informação de Agravos de Notificação (SINAN), por meio do Sistema de Informação da Secretária de Estado de Saúde de Mato Grosso (DwWeb - SES-MT), no período de 2009 a 2019. As variáveis foram analisadas no programa Epi Info. Resultados: Durante o período do estudo foram notificados 875 casos, com uma maior ocorrência em 2009 e 2013. A maioria dos casos ocorreram em crianças e adolescentes pardos (54,40\%) que residiam na zona urbana (90,63\%), sem comorbidades (99,31\%), sendo que 9,26\% evoluíram para óbito. Não foi observado diferença no número de registros nas análises por faixa etária. A meningite asséptica liderou os casos (35,43\%) seguida da meningite não especificada (29,71\%) e, apenas $3,77 \%$ dos pacientes apresentaram menincococcemia, com um desfecho de óbito de 45,45\%. A metodologia diagnóstica mais utilizada foi a quimiocitologia do líquor $(60,11 \%)$ e a cultura $(11,89 \%)$. Conclusão: os casos de meningite acompanhados de meningococcemia estão associados com as maiores taxas de mortalidade. Estes dados corroboram a importância de ações profiláticas e aprimoramento no manejo da doença. Ademais, em um grande número de casos não foi encontrado ou descrito o agente etiológico, de forma a prejudicar os dados quanto as principais etiologias da meningite no estado.

Palavras-chave: Meningite; Meningococcemia; Epidemiologia; Perfil Epidemiológico;

\section{ABSTRACT}

Objective: present study aimed to verifying the epidemiological and 
1. Silva HCG, Mezarobba N. Meningite no Brasil em 2015: O panorama da atualidade. Arq. Catarin Med. 2018; 47(1): 34-46. clinical profile of meningitis in children and youths between 0 and 19 years old in the state of Mato Grosso during 2009 - 2019. Methods: retrospective analysis with data collected from the Notifiable Diseases Information System (SINAN ), through the Information System of the State Secretary of Health of Mato Grosso (DwWeb - SES-MT), from 2009 to 2019. The variables were analyzed in the Epi Info program. Results: During the study period, 875 cases were reported, with a higher occurrence in 2009 and 2013. Most cases occurred in brown children and adolescents (54.40\%) who lived in the urban area (90.63\%), without comorbidities (99.31\%), with $9.26 \%$ progressing to death. There was no difference in the number of records in the analyzes by age group. Aseptic meningitis led the cases (35.43\%) followed by unspecified meningitis (29.71\%) and only $3.77 \%$ of the patients presented menincococcemia with a death outcome of $45.45 \%$. The most widely used diagnostic methodology was cerebrospinal fluid chemotherapy (60.11\%) and culture (11.89\%). Conclusion: cases of meningitis with meningococcemia are associated with the highest mortality rates. These data corroborate the importance of prophylactic actions and improvement in the ways of handling of the disease. In addition, in a large number of cases the etiologic agent was not found or described, in order to damage the data regarding the main etiologies of meningitis in the state.

Keywords: Meningitis; Meningococcemia; epidemiology; epidemiological profile;

\section{INTRODUÇÃO}

É notório o significante crescimento da obesidade configurandose ultimamente como uma pandemia, ocasionando o aumento da prevalência de doenças crônicas associadas; a cirurgia bariátrica é o tratamento mais eficaz na redução de peso e resolução de comorbidades na população obesa mórbida ${ }^{1}$, porém é a forma mais invasiva para alcançar esse resultado; dessa forma expõe o paciente a uma maior taxa de complicações. Dentre as diferentes técnicas operatórias o bypass gástrico em $Y$ de Roux é considerado o padrão 
2. Guimarães ILB, Guimarães MLB, Moreira ACA. Perfil epidemiológico da meningite em crianças. Revista Norte Mineira de Enfermagem. 2014; 3(1): 1-7.

3. Paim ACB, Gregio MM, Garcia SP. Perfil epidemiológico da meningite no estado de Santa Catarina no período de 2008 a 2018. Arq. Catarin Med. 2019; 48(4): 111-125.

4. Mace SE. Acute bacterial meningitis. Emerg Med Clin North Am. 2008; 26(2):281- 317

5. Cordeiro, AP. Pesquisa de biomarcadores e alvos terapêuticos para as meningitespor meio da proteômica comparativa do líquor de pacientes. (Dissertação de Mestrado). Belo Horizonte: Fundação Oswaldo Cruz, Centro de Pesquisas René Rachou; 2013. ouro, correspondendo a aproximadamente $45 \%$ das operações para tratamento da obesidade mórbida realizadas no mundo ${ }^{2}$. A hérnia de Petersen, é uma complicação possível em pacientes submetidos ao bypass gástrico; é um tipo específico de hérnia interna, no qual o intestino delgado migra entre o mesocólon transverso e o mesentério da alça alimentar, anastomosada ao pouch gástrico ${ }^{3}$, essa migração da alça intestinal pelo espaço de Petersen, que pode chegar a $14 \%$ dos pacientes operados ${ }^{4}$, pode evoluir com obstrução do trânsito intestinal alto, diminuição da irrigação vascular da alça, podendo apresentar sofrimento de alça, isquemia e necrose da alça intestinal. A apresentação clínica é caracterizada por sintomas inespecíficos de obstrução como náuseas, vômitos logo após alimentação ${ }^{9}$ inapetência, odinofagia, dor abdominal em andar superior irradiada para dorso que leva a um retardo no diagnóstico, com possibilidade de uma lesão intestinal evoluindo inclusive com óbito ${ }^{5}$.

\section{MÉTODOS}

Trata-se de um estudo retrospectivo caracterizado por abordagem quantitativa a partir de dados de crianças e adolescentes de 0 a 19 anos com casos notificados de meningite obtidos do Sistema de Informação de Agravos de Notificação (SINAN), por meio do Sistema de Informação da Secretária de Estado de Saúde de Mato Grosso (DwWeb - SES-MT), no período de 2009 a 2019.

As variáveis analisadas foram: ano de notificação, classificação da meningite, presença de meningococcemia, critério de confirmação, presença de doenças preexistentes, evolução do caso, óbito, óbito por meningite, idade, raça e zona de residência. Foram excluídos dados com informações em branco ou ignoradas.

Nas análises de associação ao óbito por meningite foram descritas e dicotomizadas as seguintes variáveis: ano da notificação, meningococcemia, critério de confirmação, doenças preexistentes imunossupressoras, faixa etária, zona de residência e raça.

Os dados coletados foram inseridos em planilhas do Microsoft Excel ${ }^{\circledR}$, posteriormente submetidos ao programa Epi Info ${ }^{\circledR}$ para análise e elaboração das tabelas de frequência e, por fim, descritos em tabelas do Microsoft Word ${ }^{\circledR}$. 
A análise bivariada foi realizada por meio do cálculo de risco relativo (RR) e respectivos intervalos de confiança de 95\% (IC 95\%) e o p-valor foi calculado pelo teste qui-quadrado pelo método de Mantel-Haenszel, com o nível de significância estabelecido como 5\%.

\section{RESULTADOS}

Os resultados desse estudo mostram que foram notificados 875 casos de meningite no estado de Mato Grosso em crianças e adolescentes com idade entre 0 a 19 anos no período entre 2009 a 2019. Conforme apresentado no gráfico 1, o número de casos notificados foi maior em 2013 e 2009 , com tendência posterior de queda, sendo os menores índices registrados em 2016 e 2019.

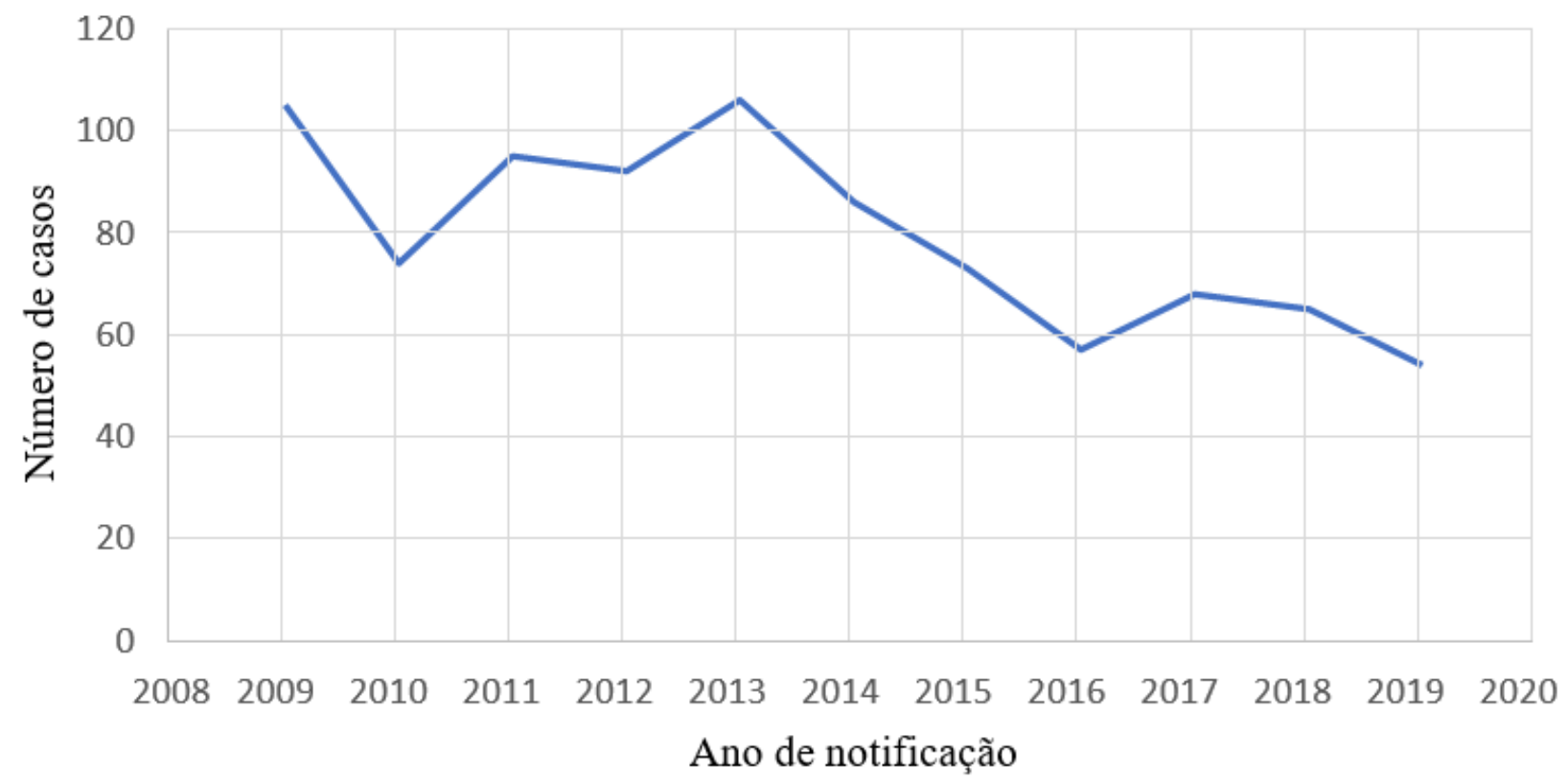

Gráfico 1. Número de casos registrados de meningite em crianças e adolescentes de 0 e 19 anos entre 2009 e 2019 no estado de Mato Grosso.

$\mathrm{Na}$ análise dos resultados de acordo com a faixa etária, não foi observado diferença na incidência de meningite em crianças com idade $<5$ anos (49,83\%) e $\geqslant 5$ anos (50,1\%). Os dados referentes à raça/cor mostram uma maior incidência entre pardos $(54,40 \%)$, seguido por brancos (38,17\%), pretos (3,77\%), amarelos (1,83\%) e indígenas $(1,83 \%)$. Em relação a Zona de residência, 90,63\% (793) moram na zona urbana e apenas 9,37\% (82) são residentes da zona rural (Tabela 1). 
Tabela 1: Distribuição dos casos de meningite de acordo com as características sociodemográficas das crianças e adolescentes com meningite entre 2009 e 2019 no Estado de Mato Grosso

\begin{tabular}{lcc}
\hline Variáveis & $\mathbf{N}$ & $\mathbf{\%}$ \\
\hline Faixa etária & & \\
$<5$ anos & 436 & 49,83 \\
$\geq 5$ anos & 439 & 50,17 \\
Raça/cor & & \\
Amarela & 16 & 1,83 \\
Branca & 334 & 38,17 \\
Indígena & 16 & 1,83 \\
Parda & 476 & 54,40 \\
Preta & 33 & 3,77 \\
Zona residência & & \\
Rural & 82 & 9,37 \\
Urbana/periurbana & 793 & 90,63 \\
Total & 875 & 100,00 \\
\hline
\end{tabular}

Quanto a classificação da meningite, a meningite asséptica lidera como a causa mais frequente, com $35,43 \%$ dos casos, seguida da meningite não especificada $(29,71 \%)$ e da bacteriana $(16,11 \%)$, somando todas $81,25 \%$ dos casos. Entre os agentes menos comuns, estão a meningite por tuberculose (0,46\%) e meningite por hemófilo (0,69\%). (Tabela 2$)$.

Tabela 2: Distribuição dos casos de acordo com a classificação da meningite em crianças e adolescentes entre 0 e 19 anos entre 2009 e 2019 no Estado de Mato Grosso

\begin{tabular}{lcc}
\hline Variáveis & N & \% \\
\hline Classificação meningite & 310 & 35,43 \\
Meningite asséptica & 260 & 29,71 \\
Meningite não especificada & 141 & 16,11 \\
Meningite bacteriana & 52 & 5,94 \\
Meningite meningocócica & 44 & 5,03 \\
Meningite por pneumococos & 25 & 2,86 \\
Meningite de outra etiologia & 22 & 2,51 \\
Meningococemia & 11 & 1,26 \\
Meningite meningocócica com & & 0,69 \\
meningococemia & 6 & 0,46 \\
Meningite por hemófilo & 4 & 100,00 \\
Meningite tuberculosa & 875 & \\
\hline
\end{tabular}


Apenas $3,77 \%$ dos pacientes cursaram com meningococcemia. 0 critério de confirmação diagnóstica mais utilizado foi o teste quimiocitológico do líquor (60,11\%), seguido da cultura (11,89\%) e diagnóstico clínico (10,29\%) (Tabela 3).

Tabela 3: Distribuição dos casos de acordo com a presença de meningococcemia e critério de confirmação de meningite em crianças e adolescentes entre 2009 e 2019 no Estado de Mato Grosso.

\begin{tabular}{lcc}
\hline Variáveis & $\mathbf{N}$ & $\mathbf{\%}$ \\
\hline Meningococemia & & \\
Não & 842 & 96,23 \\
Sim & 33 & 3,77 \\
Critério de confirmação & & \\
Ag. Látex & 42 & 4,8 \\
Bacterioscopia & 47 & 5,37 \\
Clínico & 90 & 10,29 \\
Clínico-epidemiologico & 31 & 3,54 \\
Cultura & 104 & 11,89 \\
Isolamento viral & 1 & 0,11 \\
Outros & 20 & 2,29 \\
PCR & 14 & 1,6 \\
Quimiocitológico do liquor & 526 & 60,11 \\
Total & 875 & 100,00 \\
\hline
\end{tabular}

A maior parte dos pacientes afetados não possuíam qualquer comorbidade $(99,31 \%)$ e evoluíram com alta do quadro (88,46\%). A análise dos dados mostra que 9,26\% evoluíram para óbito por meningite e $2,29 \%$ por outras causas (Tabela 4).

Tabela 4: Presença de doenças imunodepressoras e evolução do caso em crianças e adolescentes com meningite entre 2009 e 2019

\begin{tabular}{lcc}
\hline Variáveis & $\mathbf{N}$ & $\mathbf{\%}$ \\
\hline $\begin{array}{l}\text { Doenças pré-existentes } \\
\text { imunodepressoras }\end{array}$ & & \\
$\quad$ Não & 869 & 99,31 \\
$\quad$ Sim & 6 & 0,69 \\
Evolução do caso & 774 & 88,46 \\
$\quad$ Alta & 81 & 9,26 \\
$\quad$ Óbito por meningite & 20 & 2,29 \\
$\quad$ Obito por outra causa & & \\
Obito & 774 & 88,46 \\
$\quad$ Não & 101 & 11,54 \\
$\quad$ Sim & 794 & 90,74 \\
Obito por meningite & 81 & 9,26 \\
$\quad$ Não & 875 & 100,00 \\
$\quad$ Sim & & \\
Total & & \\
\hline
\end{tabular}


As análises de associação entre as variáveis e o desfecho em óbito mostram um risco de 5,79 vezes maior na presença de meningococcemia (Tabela 5).

Tabela 5. Fatores prognósticos para o óbito entre casos confirmados de meningite entre indivíduos de 0 a 19 anos, em Mato Grosso: 2009-2019

\begin{tabular}{|c|c|c|c|c|c|}
\hline \multirow[t]{2}{*}{ Variável } & \multirow[t]{2}{*}{ n (\%) } & \multicolumn{2}{|c|}{ Óbito } & \multirow[t]{2}{*}{ RR (IC95\%) } & \multirow[t]{2}{*}{$\mathbf{P}$} \\
\hline & & Sim & Não & & \\
\hline \multicolumn{6}{|l|}{ Ano da notificação } \\
\hline 2009 a 2014 & $\begin{array}{c}558 \\
(63,77)\end{array}$ & $54(9,68)$ & $\begin{array}{c}504 \\
(90,32)\end{array}$ & $1,13(0,73-1,76)$ & 0,56 \\
\hline 2015 a 2019 & $\begin{array}{c}317 \\
(36,23)\end{array}$ & $27(8,52)$ & $\begin{array}{c}290 \\
(91,48)\end{array}$ & 1,00 & \\
\hline \multicolumn{6}{|l|}{ Meningococcemia } \\
\hline Sim & $33(3,77)$ & $15(45,45)$ & $18(54,55)$ & $5,79(3,73-9,00)$ & $<0,01$ \\
\hline Não & $\begin{array}{c}842 \\
(96,23)\end{array}$ & $66(7,84)$ & $\begin{array}{c}776 \\
(92,16)\end{array}$ & 1,00 & \\
\hline \multicolumn{6}{|l|}{ Confirmação } \\
\hline Clínico & $\begin{array}{c}121 \\
(13,83)\end{array}$ & $12(9,92)$ & $\begin{array}{c}109 \\
(90,08)\end{array}$ & $1,08(0,60-1,93)$ & 0,78 \\
\hline Laboratorial & $\begin{array}{c}754 \\
(86,17)\end{array}$ & $69(9,26)$ & $\begin{array}{c}685 \\
(90,85)\end{array}$ & 1,00 & \\
\hline \multicolumn{6}{|l|}{$\begin{array}{l}\text { Doenças } \\
\text { preexistentes } \\
\text { imunossupressoras }\end{array}$} \\
\hline $\operatorname{Sim}$ & $6(0,69)$ & $0(0,00)$ & $6(0,76)$ & 0,00 & 0,43 \\
\hline Não & $\begin{array}{c}869 \\
(99,31)\end{array}$ & $81(9,32)$ & $\begin{array}{c}788 \\
(90,74)\end{array}$ & 1,00 & \\
\hline \multicolumn{6}{|l|}{ Faixa etária } \\
\hline$<5$ anos & $\begin{array}{c}436 \\
(49,83)\end{array}$ & $44(10,09)$ & $\begin{array}{c}392 \\
(89,91)\end{array}$ & $1,19(0,78-1,81)$ & 0,39 \\
\hline$\geq 5$ anos & $\begin{array}{c}439 \\
(50,17)\end{array}$ & $37(8,43)$ & $\begin{array}{c}402 \\
(91,57)\end{array}$ & 1,00 & \\
\hline \multicolumn{6}{|l|}{ Zona de residência } \\
\hline Rural & $82(9,37)$ & $9(11,11)$ & $73(89,02)$ & $1,20(0,62-2,32)$ & 0,57 \\
\hline Urbana/periurbana & $\begin{array}{c}793 \\
(90,63)\end{array}$ & $72(9,08)$ & $\begin{array}{c}721 \\
(90,92)\end{array}$ & 1,00 & \\
\hline \multicolumn{6}{|l|}{ Raça do paciente } \\
\hline Branca/parda & $\begin{array}{c}810 \\
(92,57)\end{array}$ & $73(9,01)$ & $\begin{array}{c}737 \\
(90,99)\end{array}$ & $0,73(0,36-1,45)$ & 0,37 \\
\hline Outras & $65(7,43)$ & $8(12,31)$ & $57(87,69)$ & 1,00 & \\
\hline
\end{tabular}


1. Silva HCG, Mezarobba N. Meningite no Brasil em 2015: O panorama da atualidade. Arq. Catarin Med. 2018; 47(1): 34-46.

3. Paim ACB, Gregio MM, Garcia SP. Perfil epidemiológico da meningite no estado de Santa Catarina no período de 2008 a 2018. Arq. Catarin Med. 2019; 48(4): 111-125.

12. Gandin NIG, Puricelli RBC, Rodrigues MIS, Deitos R, Silva AMR, Souza KR, Farias RE, Barreto G. Meningites em Geral e Doença Meningococcica. Florianópolis: Secretária de Estado da Saúde; 2014

13. Emmerick ICM, Campos MR, Schramm, Silva RS, Costa MFS. Estimativas corrigidas de casos de meningite, 2008-2009. Epidemiol. Serv. Saúde, Brasília. 2014; 23(2):215- 226.

14 Griffiths MJ McGill F, Solomon T.

Management of acute meningitis. Clin Med

(Lond). 2018; 18(2):164-169.

15. Rodrigues BEM. Meningite: Perfil epidemiológico da doença no Brasil nos anos de 2007 a 2013. (Monografia). Brasília: Centro Universitário de Brasília; 2015.

16. Fontes FLL. Epidemiological aspects of meningite in the state of Piauí: 2007 to 2017. ReonFacema. 2018; 4(3): 1302-1309.

17. GBD 2016 Meningitis Collaborators. Global, regional, and national burden of meningitis, 1990-2016: a systematic analysis

for the Global Burden of Disease Study 2016. Lancet Neurol. 2018;17(12):1061-1082.

18. Dazzi MC, Zatti CA, Baldissera R. Perfil dos casos de meningites ocorridas no Brasil de 2009 a 2012. Revista UNINGÁ. 2014; 19(3): 33-36

\section{DISCUSSÃO}

A meningite pode ser uma doença grave, de rápida evolução, e alta taxa de morbimortalidade, cujo diagnóstico precoce interfere diretamente no prognóstico do paciente ${ }^{12,13,14}$. Seu perfil etiológico tem passado por mudanças constantes desde a implementação da imunização pelo Programa Nacional de Imunização (PNI) contra agentes bacterianos e virais s.15,16. $^{3,1}$

Os dados do nosso estudo mostram uma variação com picos acima do esperado em 2013 mesmo após a implementação da vacina, contrastando com os dados de Rodrigues (2015) que observou o menor número de casos registrados no mesmo período, sugerindo assim um surto endêmico no estado. A partir de então a queda na incidência seguiu conforme a média nacional e mundial ${ }^{15,17}$.

Nas análises de acordo com a faixa etária, o nosso estudo mostrou resultados similares a outro publicado previamente. Em ambos os estudos foi observado aproximadamente a mesma porcentagem de casos entre maiores e menores de 5 anos $^{15}$.

Por outro lado, o número de infecções em relação à cor da pele mostrou-se oposta a dois estudos anteriores sobre a meningite no Brasil, que mostraram a raça branca como a mais atingida (54,5\% e $43,05 \%$ respectivamente), seguida da raça parda (39\% e $29,7 \%$ respectivamente), enquanto que em nosso estudo a maior incidência foi em pardos (54,40\%), seguido de brancos $(38,17 \%)^{1,18}$.

Trabalhos com dados do Brasil mostram as meningites assépticas como as mais incidentes, com $42,1 \%$ dos casos, seguidas das meningites bacterianas com $35,6 \%$ dos casos. Nossos resultados também trazem a meningite asséptica como a mais comum com $35,43 \%$ dos casos, entretanto há uma divergência na segunda mais incidente que ficou representada pelas meningites não especificadas com $29,71 \%$ dos casos, seguidas das bacterianas com 16,11\%. É possível observar também em outros estudos a meningite asséptica como a mais comum, porém há discordâncias quanto ao segundo subtipo mais incidente $\mathrm{e}^{3,16,18}$.

Conforme o esperado, observamos uma baixa taxa de meningites por Haemophilus Influenzae tipo B, antes principal causa de meningite 
1. Silva HCG, Mezarobba N. Meningite no Brasil em 2015: O panorama da atualidade. Arq. Catarin Med. 2018; 47(1): 34-46.

3. Paim ACB, Gregio MM, Garcia SP. Perfil epidemiológico da meningite no estado de Santa Catarina no período de 2008 a 2018. Arq. Catarin Med. 2019; 48(4): 111-125.

9. Ministério da Saúde (BR). Secretaria de Vigilância em Saúde. Coordenação-Geral de Desenvolvimento da Epidemiologia em Serviços. Guia de Vigilância em Saúde. v.1. Brasília; 2017: 35-70.

15. Rodrigues BEM. Meningite: Perfil epidemiológico da doença no Brasil nos anos de 2007 a 2013. (Monografia). Brasília: Centro Universitário de Brasília; 2015.

16. Fontes FLL. Epidemiological aspects of meningite in the state of Piauí: 2007 to 2017. ReonFacema. 2018; 4(3): 1302-1309.

19. Ballalai I, Bravo F. Imunização: tudo o que você sempre quis saber. 3 ed. Rio de Janeiro: RMCOM, 2017.

20. Ferreira JHS, Gomes AAS, Oliveira CM, Bonfim CV. Tendência e aspectos epidemiológicos das meningites bacterianas em crianças. Rev enferm UFPE online, Recife. 2015; 9(7): 8534-8541.

21. Coureuil Mathieu, Join-Lambert $O$, Lécuye $\mathrm{H}$, Bourdoulous $\mathrm{S}$, et al. Pathogenesis of

Meningococcemia. Cold Spring Harb Perspect Med. 2013; 3(6): 1-14

22. Berezin EN. Epidemiologia da Infecção Meningocócica. São Paulo: AlamTec; 2015. no Brasil até $1990^{15}$, devido a introdução da vacina contra esta bactéria e de outros agentes bacterianos que possuem vacina como a meningite por tuberculose ( $0,46 \%$ ). Já as vacinas contra o pneumococo e meningococo foram incorporadas mais recentemente, em 2010, e por conta disso estes agentes continuam tendo certa prevalência na população. $1,15,19,20$

Deve-se aventar a possibilidade de que, apesar da meningite de origem viral ser a causa mais comum, ela pode sofrer subnotificações, tendo em vista seu curso majoritariamente benigno e autolimitado, muitas vezes curando-se antes de um diagnóstico médico ${ }^{16}$. Além disso, os métodos de pesquisa viral são pouco acessíveis e portanto, pouco utilizados, o que é confirmado pelos dados deste estudo, no qual os meios para confirmação diagnóstica menos utilizados incluem o isolamento viral e o PCR, assim como demonstrado em outros trabalhos. ${ }^{15,20}$

Os métodos confirmatórios mais comuns citados nesse estudo são reforçados por outros estudos epidemiológicos, que seguem a mesma sequência das ferramentas diagnósticas, sendo o quimiocitológico o mais utilizado, seguido pela cultura e exame clínico. ${ }^{1,3,15,20}$

Dentre os indivíduos acometidos pela meningite nesse estudo, apenas $3,77 \%$ apresentaram meningococcemia associada, condição frequentemente fatal ${ }^{21}$. Em nosso estudo a meningococcemia mostrou-se a única variável associada à mortalidade dos pacientes. Esses resultados podem ser comprovados por dados publicados pelo Ministério da Saúde e pela Sociedade Brasileira de Pediatria, que apontam uma taxa de letalidade de aproximadamente $50 \%$ nos casos que cursam com esta forma da doença, com a maioria dos óbitos ocorrendo nas primeiras 48 horas. ${ }^{9,22}$

\section{CONCLUSÃO}

Aatualização contínua do perfil epidemiológico se faz necessária para verificação do sucesso ou falha das medidas preventivas e manejos efetuados, assim como para o planejamento de novas intervenções que possam ser necessárias. 0 principal subtipo encontrado foi a meningite asséptica seguida da não especificada e da bacteriana, 
portanto pode-se observar uma grande quantidade de casos no qual não foi encontrado ou descrito o agente etiológico, dessa forma fica clara a necessidade de investigações mais aprofundadas para identificação do agente causador da meningite no estado de MT. A única variável que demonstrou diferença estatística no desfecho óbito foi a meningococcemia, tal fato evidencia a necessidade de uma melhor forma de manejo dessa forma grave da doença, seja por meio da profilaxia ou mediante aprimoração da terapêutica desses pacientes.

\section{REFERÊNCIAS}

1. Silva HCG, Mezarobba N. Meningite no Brasil em 2015: O panorama da atualidade. Arq. Catarin Med. 2018; 47(1): 34-46.

2. Guimarães ILB, Guimarães MLB, Moreira ACA. Perfil epidemiológico da meningite em crianças. Revista Norte Mineira de Enfermagem. 2014; 3(1): 1-7.

3. Paim ACB, Gregio MM, Garcia SP. Perfil epidemiológico da meningite no estado de Santa Catarina no período de 2008 a 2018. Arq. Catarin Med. 2019; 48(4): 111-125.

4. Mace SE. Acute bacterial meningitis. Emerg Med Clin North Am. 2008; 26(2):281- 317.

5. Cordeiro, AP. Pesquisa de biomarcadores e alvos terapêuticos para as meningitespor meio da proteômica comparativa do líquor de pacientes. (Dissertação de Mestrado). Belo Horizonte: Fundação Oswaldo Cruz, Centro de Pesquisas René Rachou; 2013.

6. Damiani D, Furlan MC, Damiani D. Meningite asséptica. Rev Bras Clin Med. 2012; 10(1): 46-50.

7. Santos GPL. Meningites e meningoencefalites assépticas: estudos de detecção e variabilidade genética de agentes etiológicos virais. (Tese de Doutorado). Rio de Janeiro: Fundação Oswaldo Cruz, Instituto Nacional de Controle de Qualidade em Saúde; 2012.

8. Reed UC, Marques-Dias MJ. Meningites. Neurologia. Barueri, SP: Manole; 2012. p. 256-263.

9. Ministério da Saúde (BR). Secretaria de Vigilância em Saúde. Coordenação-Geral de Desenvolvimento da Epidemiologia em Serviços. Guia de Vigilância em Saúde. v.1. Brasília; 2017: 35-70.

10. Guedes JC, Carvalho IP, Barbosa JJ, Missel LA, Pena LTG, Costa LR, Fortes CPDD. CCC Rev Ped SOPERJ. 2018; 18(2): 24-27.

11. Vieira MACS, Neto ASL, Costa CHN, Costa DL,Amaral EJLS, et al. Proposta de abordagem simplificada 
para suspeitas de meningites: relato de experiência de serviço de referência do estado do Piauí, 2007-2016. Epidemiol. Serv. Saude. 2018; 27(3):e2017329.

12. Gandin NIG, Puricelli RBC, Rodrigues MIS, Deitos R, Silva AMR, Souza KR, Farias RE, Barreto G. Meningites em Geral e Doença Meningococcica. Florianópolis: Secretária de Estado da Saúde; 2014.

13. Emmerick ICM, Campos MR, Schramm, Silva RS, Costa MFS. Estimativas corrigidas de casos de meningite, 2008-2009. Epidemiol. Serv. Saúde, Brasília. 2014; 23(2):215- 226.

14. Griffiths MJ, McGill F, Solomon T. Management of acute meningitis. Clin Med (Lond). 2018; 18(2):164-169.

15. Rodrigues BEM. Meningite: Perfil epidemiológico da doença no Brasil nos anos de 2007 a 2013. (Monografia). Brasília: Centro Universitário de Brasília; 2015.

16. Fontes FLL. Epidemiological aspects of meningite in the state of Piauí: 2007 to 2017. ReonFacema. 2018; 4(3): 1302-1309.

17. GBD 2016 Meningitis Collaborators. Global, regional, and national burden of meningitis, 1990-2016: a systematic analysis for the Global Burden of Disease Study 2016. Lancet Neurol. 2018;17(12):10611082.

18. Dazzi MC, Zatti CA, Baldissera R. Perfil dos casos de meningites ocorridas no Brasil de 2009 a 2012. Revista UNINGÁ. 2014; 19(3): 33-36.

19. Ballalai I, Bravo F. Imunização: tudo o que você sempre quis saber. 3 ed. Rio de Janeiro: RMCOM, 2017.

20. Ferreira JHS, Gomes AAS, Oliveira CM, Bonfim CV. Tendência e aspectos epidemiológicos das meningites bacterianas em crianças. Rev enferm UFPE online, Recife. 2015; 9(7): 8534-8541.

21.Coureuil Mathieu,Join-Lambert O, Lécuyer H,Bourdoulous S, et al.Pathogenesis of Meningococcemia. Cold Spring Harb Perspect Med. 2013; 3(6): 1-14.

22. Berezin EN. Epidemiologia da Infecção Meningocócica. São Paulo: AlamTec; 2015. 